http://dx.doi.org/10.35381/r.k.v4i1.464

\title{
El clima organizacional y su incidencia en la motivación del Talento Humano
}

The organizational climate and its impact on the motivation of Human Talent

\author{
Diana Elizabeth Valencia Naranjo \\ devalencian@psg.ucacue.edu.ec \\ Universidad Católica de Cuenca, Cuenca \\ Ecuador \\ https://orcid.org/0000-0001-6237-1024 \\ Juan Carlos Erazo Álvarez \\ jcerazo@ucacue.edu.ec \\ Universidad Católica de Cuenca, Cuenca, \\ Ecuador \\ https://orcid.org/0000-0001-6480-2270 \\ Cecilia Ivonne Narváez Zurita \\ inarvaez@ucacue.edu.ec \\ Universidad Católica de Cuenca, Cuenca \\ Ecuador \\ https://orcid.org/0000-0002-7437-9880
}

Recibido: 11 de agosto de 2019

Aprobado: 28 de agosto de 2019

\section{RESUMEN}

El talento humano es el principal elemento de una organización, donde el Clima organizacional y la motivación son fundamentales para el éxito y la consecución de sus objetivos. Problemas precisamente identificados en la Unidad de análisis de la presente investigación. Para la verificación de la problemática identificada se utilizó un diseño de investigación mixto exploratorio secuencial (dexplos) derivativa ya que se realizó un análisis cualitativo de los datos recolectados cuantitativamente, según el enfoque fue descriptiva. Los resultados obtenidos dan cuenta de la importancia de generar políticas para que sean aplicadas de forma constante y permanente mediante la utilización de un plan de incentivos y recompensas.

Descriptores: Clima; Organizacional; Motivación; Talento humano; Satisfacción. 


\begin{abstract}
The human talent is the main element of an organization, where Work Climate and motivation are fundamental to the success and achievement of its objectives. Problems precisely identified in the Unit of analysis of the present investigation. For the verification of the identified problem, a mixed sequential exploratory research design (dexplos) was used since a qualitative analysis of the data collected quantitatively was performed, according to the approach was descriptive. The results obtained account for the importance of generating policies so that they are applied consistently and permanently through the use of an incentive and reward plan.
\end{abstract}

Descriptors: Working environment; Organizational; Motivation; Human talent; Satisfaction.

\title{
INTRODUCCIÓN
}

La Unidad de análisis de la presente investigación es Motricentro Cía. Ltda, una compañía privada fundada en 1972 con 45 años en el mercado que pone a su disposición vehículos y repuestos originales KIA. Productos para el cuidado automotriz en las marcas Bosch y $3 \mathrm{M}$. Comercializamos llantas General, Continental y Barum para todo tipo de vehículo; además poseemos modernos talleres para vehículos y tecnicentro especializado en la Ciudad de Cuenca y Loja, ofrece vehículos con diseños innovadores, de bajo consumo de combustible y altos indicadores de seguridad, respaldados por la marca KIA MOTORS que ha sido la marca de mayor crecimiento en el mercado mundial, por ofertar al público vehículos que están pensados en la comodidad y seguridad de sus usuarios. Los problemas identificados se mencionan a continuación:

La empresa ha perdido competitividad dentro del nicho de mercado en la provincia del Azuay, ya que se nota el desinterés de los empleados del Departamento de Ventas del departamento de vehículos, la competencia brinda más calidad en la atención.

La Estructura Organizacional existe y es funcional a la empresa, pero no es socializada adecuadamente provocando confusión en el personal y dando paso a que todos realicen las mismas actividades viéndose enfrentados los trabajadores en el desempeño de su labor. 
Dado que la Responsabilidad va ligada a la autonomía en la ejecución de la actividad encomendada y guarda a su vez, una estrecha relación con el tipo de supervisión que se ejerza sobre las funciones, los trabajadores no asumen compromisos con responsabilidad sino más bien a convenir, según el caso provocando así un mal ambiente laboral entre ellos y el entorno.

Si estamos desarrollando la actividad que nos place hacer, nuestra labor siempre será importante, manteniendo la idea de que estamos haciendo un aporte importante a la organización, pero debe ir de la mano de una recompensa que se recibe a cambio del esfuerzo y la dedicación, esto no ha venido sucediendo ya que fueron disminuidos los salarios, comisiones por ventas, incentivos monetarios y no monetarios, y los cupos se incrementaron, definitivamente esto desmotiva al personal quienes ya no trabajan con la misma energía y otros ya han renunciado, los empleados que aun colaboran con la empresa han manifestado su inconformidad.

Las Relaciones Laborales se ven afectadas notablemente entre compañeros, existen competitividad constante y manifestaciones de diferencias entre los empleados del departamento de ventas, por atender a un cliente y tratar de realizarle la venta siento claramente visible del deterioro del respeto entre los colaboradores creando un clima organizacional pesado y hostil.

\section{Clima Organizacional y Motivación, dos componentes esenciales en las organiza- ciones.}

El clima organizacional y la motivación son dos importantes indicadores del funcionamiento fisiológico, psicológico y autorrealización del talento humano en las empresas. Hoy en día las organizaciones juegan un papel importante dentro de nuestro entorno, las investigaciones vinculadas al tema, reportan una directa asociación entre estas variables y un nivel óptimo de funcionamiento en cada una de ellas en entidades exitosas. Por ello es que es indispensable el estudio de estos elementos ya que están estrechamente vinculados con el desempeño y la satisfacción laboral en el trabajo con el fin de fortalecer la mejora continua del ambiente, lo cual permitirá gestionar la motivación pertinente para 
brindar un servicio de calidad al cliente interno y externo de la organización, Aldana, J., \& Piña, J. (2017).

A continuación, se realiza una revisión literaria de varios autores quienes han definido el clima organizacional y la motivación a lo largo de la historia:

\section{Definiciones de Clima organizacional y Motivación.}

Tabla 1.
Autor y Año
Concepto

Davis (1981) "El clima organizacional es el ambiente en el cual los empleados trabajan, ya sea en un departamento, una unidad de trabajo o la organización entera".

(Chiavenato, Expone que "el clima organizacional es la cualidad o propiedad Clima del ambiente organizacional percibido o experimentado por los organizacional miembros de la organización y que influye en su comportamiento". , 1992, p. 75) (Goncalves, Definió el clima organizacional como las "percepciones que el tra1997, p. 103) bajador tiene de las estructuras y procesos que ocurren en un medio laboral. Estas percepciones dependen de las actividades, interacciones y otra serie de experiencia que cada miembro tenga con la empresa".

(Maslow, 1943, Sobre la motivación nos dice que es: las necesidades que el homp. 88) bre necesita satisfacer fisiológicas, seguridad, sociales, las de ego y las de autorrealización

(Robbis, 1999, Define a la Motivación como:" El deseo de hacer mucho esfuerzo p. 168) por alcanzar las metas de la organización, condicionado por la necesidad de satisfacer alguna necesidad individual".

(Chiavenato, Expresa sobre la motivación como "el resultado de la interacción 2000, p. 76) entre el individuo y la situación que lo rodea".

Asensio 2009, Define la motivación como: "el conjunto de estímulos que mueven p. 282) a una persona a realizar determinadas acciones y persistir en ellas hasta su culminación".

Fuente: Elaboración propia.

Podemos apreciar claramente en la tabla N.- 2 que si hablamos de clima organizacional todos los autores tienen coincidencias y similitudes en lo que respecta a las definiciones expresadas por cada uno de ellos. En resumen, el clima organizacional representa un vínculo o puede resultar un gran obstáculo para el desempeño de la empresa, luego de mencionados los enunciados, mencionamos que es la alta dirección, con su cultura y con 
sus sistemas de gestión, la que proporciona el terreno adecuado para un buen clima organizacional. (Montero, Erazo, Narváez y Ormaza, 2019)

El Clima, las condiciones de la empresa y las personas que forman un sistema interdependiente que tiene un impacto directo en los resultados de la organización. Los modelos de estudio de clima de las organizaciones nos plantean que existe una relación entre clima organizacional y productividad de la organización. (Narváez, Monagas y Erazo, 2019)

De la mano del clima organizacional tenemos la motivación que es uno de los factores primordiales y de mayor atención dentro de las organizaciones ya que es la que influye en el comportamiento de los individuos, la motivación es el impulso que tienen las personas para actuar ya sea de forma negativa o positiva

A principios de los años cuarenta y cincuenta es cuando se aborda el gran avance en la comprensión de las necesidades de las personas y como consecuencia de ello, empiezan a entenderse reacciones y conductas laborales hasta ese entonces inexplicables. Por eso de ahí es que Maslow (1943), es considerado como el primer autor que trata de sistematizar las necesidades humanas en un todo. Pudiéndose considerar como que dio pie a investigaciones futuras sobre la motivación en el trabajo. (p. 193)

De la teoría de Maslow (1943), en la que nos dice: "las necesidades que el hombre necesita satisfacer fisiológicas, seguridad, sociales, las de ego, autoestima y las de autorrealización" (p. 275), aunque esta definición no se refiere al ámbito laboral la amplitud de la misma nos permite aplicarle como pueden observar en la figura N.- 2. La cual trata de una jerarquía de necesidades y factores que motivan a las personas; esta jerarquía identifica cinco categorías de necesidades y considera un orden jerárquico ascendente de acuerdo a su importancia para la supervivencia y la capacidad de motivación. Podemos decir que a medida que el ser humano va satisfaciendo sus necesidades va adquiriendo otras las mismas que cambien la manera de comportarse del individuo o la modifican. 
Teoría de la Jerarquía de MASLOW (teoría de las necesidades).

Figura 1.

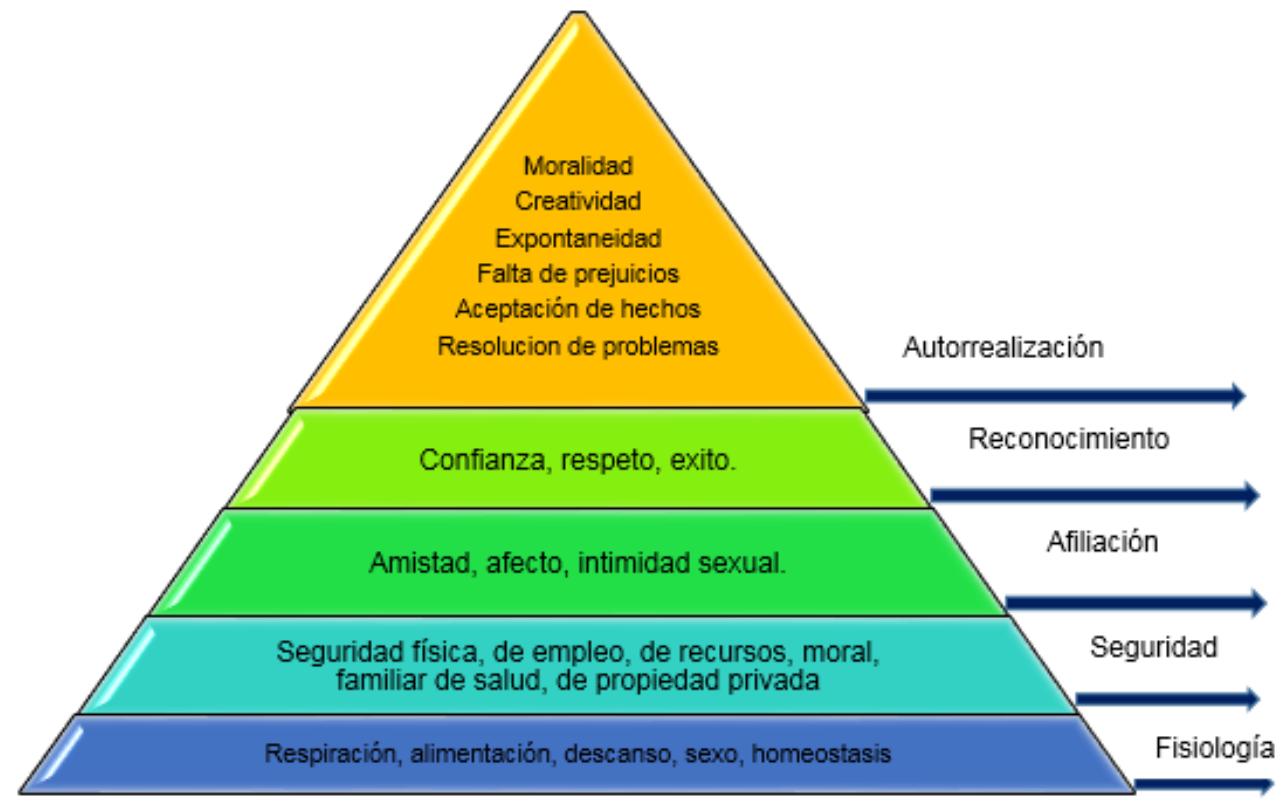

Fuente: Maslow (1943).

De acuerdo con Robbis (1999), motivación es "la voluntad de ejercer altos niveles de esfuerzo hacia las metas organizacionales, condicionados por la capacidad del esfuerzo de satisfacer alguna necesidad individual" (p.168), basándome en lo que describe el autor podemos decir que un empleado motivado es altamente productivo siendo esto beneficiosa para las organizaciones y desde este punto de vista partiremos.

\section{Importancia del Clima laboral y su incidencia en la motivación dentro de las orga- nizaciones}

El clima laboral considerado como uno de los aspectos más importantes para una empresa y lo podemos puntualizar como el conjunto de situaciones sociales y psicológicas que caracterizan a la empresa, y que inciden de manera directa en el trabajo de los colaboradores (empleados). Tenemos elementos como:

- El grado de identificación del trabajador con la empresa. 
- La forma en que los grupos laborales se constituyen y trabajan.

- El grado de conflicto, y,

- La motivación, entre otros.

El empleado, tiene necesidades que son materiales y de sentirse parte de un ambiente agradable para poder trabajar de manera óptima. Muchos empleados pueden tener todas las aptitudes necesarias para cubrir las exigencias del puesto, pero si no están en un ambiente agradable, no lograrán desarrollar su potencial.

Los expertos desde hace un tiempo vienen realizando el estudio del clima laboral y hablando de la importancia que este tiene dentro de las organizaciones, pero muchas empresas tienen falencias aun en la actualidad, los principales que se presentan es la falta de canales de comunicación el contacto que deben tener los directivos con el personal debido a las practicas antiguas donde se creía que los directivos no tenían trato con el personal de menor jerarquía dando como consecuencia que el personal se sienta parte de la organización, proyecto, departamento, etc.

Los superiores tienen conductas arrogantes que viene de la mano con llamados de atención constantes a los empleados muchas veces infundados lo que no aporta a una buena convivencia, al no reconocer e incentivar al trabajador luego de que ha realizado bien una labor, desmotiva al trabajador dado que es muy importante el reconocimiento para el empleado esto afianza lazos con la empresa. Otro elemento que suele alterar el ambiente y provocar conflictos internos es la falta de justicia entre los trabajadores que realizan una labor igual o similar, en especial en lo que se refiere a sueldos y beneficios.

Se ha vuelto muy importante el poder desenvolverse en un trabajo con un ambiente agradable, que cuando eso no sucede ya ni el dinero, beneficios sociales, bonificaciones, ni estabilidad laboral ayudan a que los profesionales comiencen a buscar nuevos empleos con desafíos a su altura, perjudicando la permanencia de buenos trabajadores talentosos capaces que pueda tener la empresa, dando pie a que exista un fracaso empresarial.

Los riesgos que genera la falta de políticas que permitan que existan buenas relaciones entre los empleados están la alta rotación de personal, baja productividad, problemas de comunicación y conflictos. Si estos problemas se dan, se recomienda que los directivos 
realicen cambios, como, reorganizar los equipos de trabajo, establecer canales de comunicación, romper con la rutina y realizar renovaciones en los diferentes departamentos. Cada día surgen nuevas empresas haciendo que el medio sea cada vez más competitivo, pero si se tiene un buen clima laboral con empleados motivados, entusiastas, colaboradores, satisfechos se tendrá una empresa exitosa ya que los empleados de sentirán comprometidos dando resultados excelentes a su empresa y claramente al. Si hablamos de clima laboral no se puede decir que sea un tema fácil porque es importantísimo que participen todos los trabajadores que conformen la organización.

\section{La satisfacción laboral, importancia del ambiente de trabajo}

Gibson, Ivancevich y Donnelly (2005) definen que la satisfacción en el trabajo es una predisposición que los sujetos proyectan acerca de sus funciones laborales. El propio autor la define como: "El resultado de sus percepciones sobre el trabajo, basadas en factores relativos al ambiente en que se desarrolla el mismo, como es el estilo de dirección, las políticas y procedimientos, la satisfacción de los grupos de trabajo, la afiliación de los grupos de trabajo, las condiciones laborales y el margen de beneficios. Aunque son muchas las dimensiones que se han asociado con la satisfacción en el trabajo, hay cinco de ellas que tienen características cruciales".

Muñoz (1990), define la satisfacción laboral como "el sentimiento de agrado o positivo que experimenta un sujeto por el hecho de realizar un trabajo que le interesa, en un ambiente que le permite estar a gusto, dentro del ámbito de una empresa u organización que le resulta atractiva y por el que percibe una serie de compensaciones psico-socioeconómicas acordes con sus expectativas". (p. 76)

Weiter (1987) p.171, "Es un estado emocional positivo y placentero resultante de la percepción subjetiva de las experiencias laborales del sujeto"

Por otra parte, el efecto de la satisfacción en el puesto en el desempeño del empleado implica y comporta satisfacción y productividad, satisfacción y ausentismo y satisfacción y rotación". 
Por último, Robbins nos explica a través del Figura N.- 2 cómo pueden los empleados expresar su insatisfacción.

\section{Ambiente de trabajo.}

Figura 2.

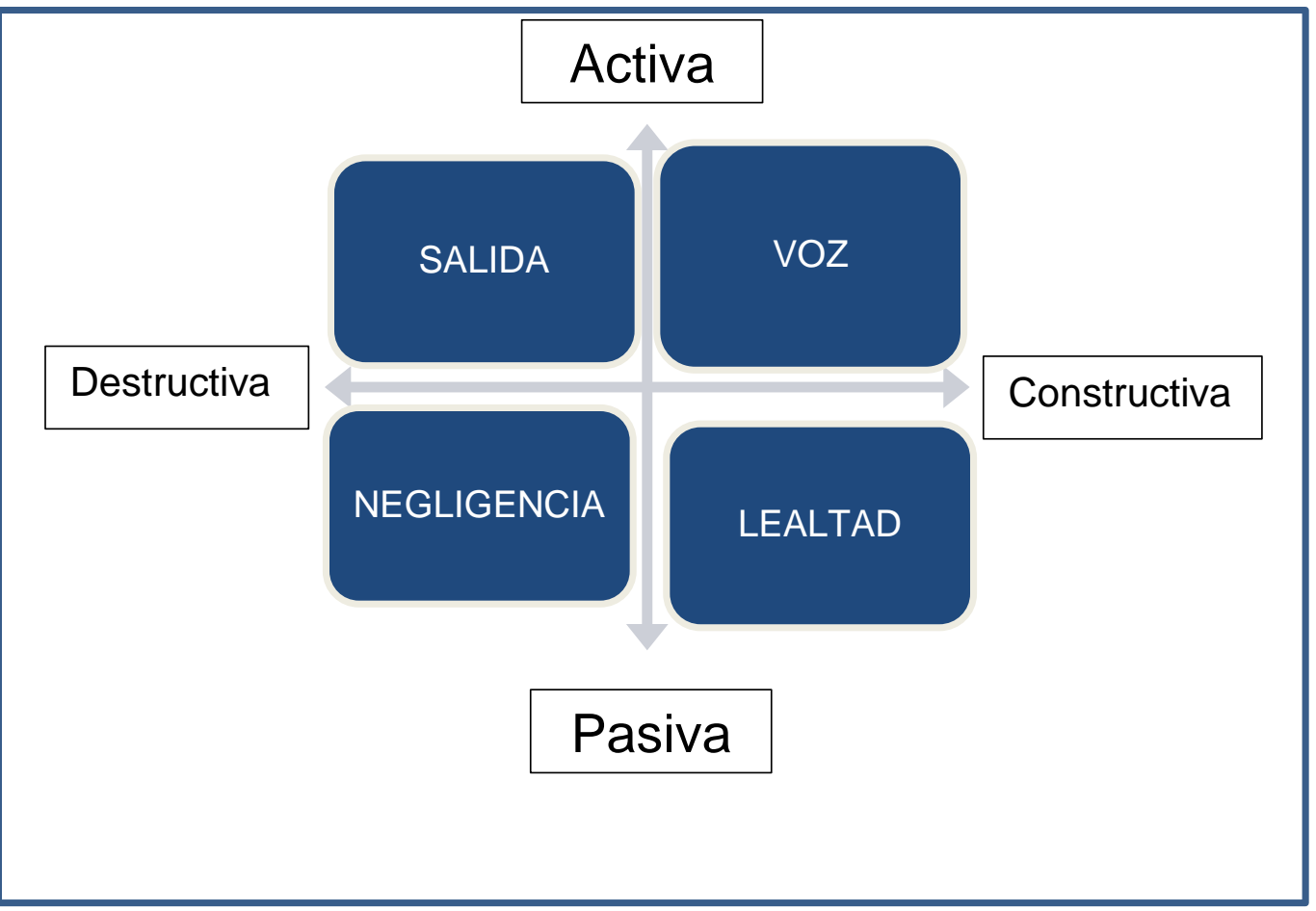

Fuente: Elaboración propia.

Salida: Es el comportamiento dirigido a dejar la empresa. Incluye buscar un nuevo empleo, además de la renuncia, desvinculación de la organización.

Voz: Intento activo y constructivo de mejorar las condiciones. Incluye la sugerencia de mejora, la discusión de problemas con los superiores y alguna forma de actividad sindical. Lealtad: Espera pasiva pero optimista de que mejoren las condiciones. Incluye hablar en favor de la organización ante las críticas externas y confiar en que la organización y su administración "harán lo correcto".

Negligencia: Permitir pasivamente que empeoren las condiciones. Incluye el ausentismo o retrasos crónicos, esfuerzos pequeños y un mayor porcentaje de errores. (Robbis, 1999, p. 197). 


\section{METODOLOGÍA}

Se empleó un diseño de investigación mixto exploratorio secuencial (dexplos) derivativa ya que se realizó un análisis cualitativo de los datos recolectados cuantitativamente para integrar los resultados obtenidos de los diferentes actores (nivel directivo y personal administrativo de las áreas de Contabilidad, Talento Humano y Ventas) y obtener conclusiones que contribuyan al mejoramiento de la satisfacción laboral, según el enfoque la investigación es descriptiva, ya que se busca especificar las características, procesos y perfiles de los diferentes actores que intervienen en la situación actual de la organización. La unidad de análisis donde se realizó la investigación es la Empresa Motricentro Cía. Ltda. Los métodos utilizados fueron; Analítico-Sintético: que consistió en descomponer y distinguir los elementos de cada variable y revisar ordenadamente cada uno de ellos por separado. El Histórico-Lógico que sirvió para llevar a cabo una comparación de los hechos sucedidos en el pasado con los actuales. El Descriptivo-Sistémico: sirvió para estudiar los fenómenos desconocidos, observarlo en su ambiente natural y luego hacer una descripción lo más detallada posible.

Se realizó encuestas a los empleados de la matriz y sus tres sucursales las mismas que están situadas una en Cuenca y dos en la ciudad de Loja, Ecuador.

Se trabajó con la totalidad del universo, 47 personas. 


\section{RESULTADOS}

Para dar solución a la problemática de la satisfacción laboral en la Unidad de Análisis se plantea la siguiente propuesta:

\section{Esquema de la propuesta de mejora.}

\section{Figura 3.}

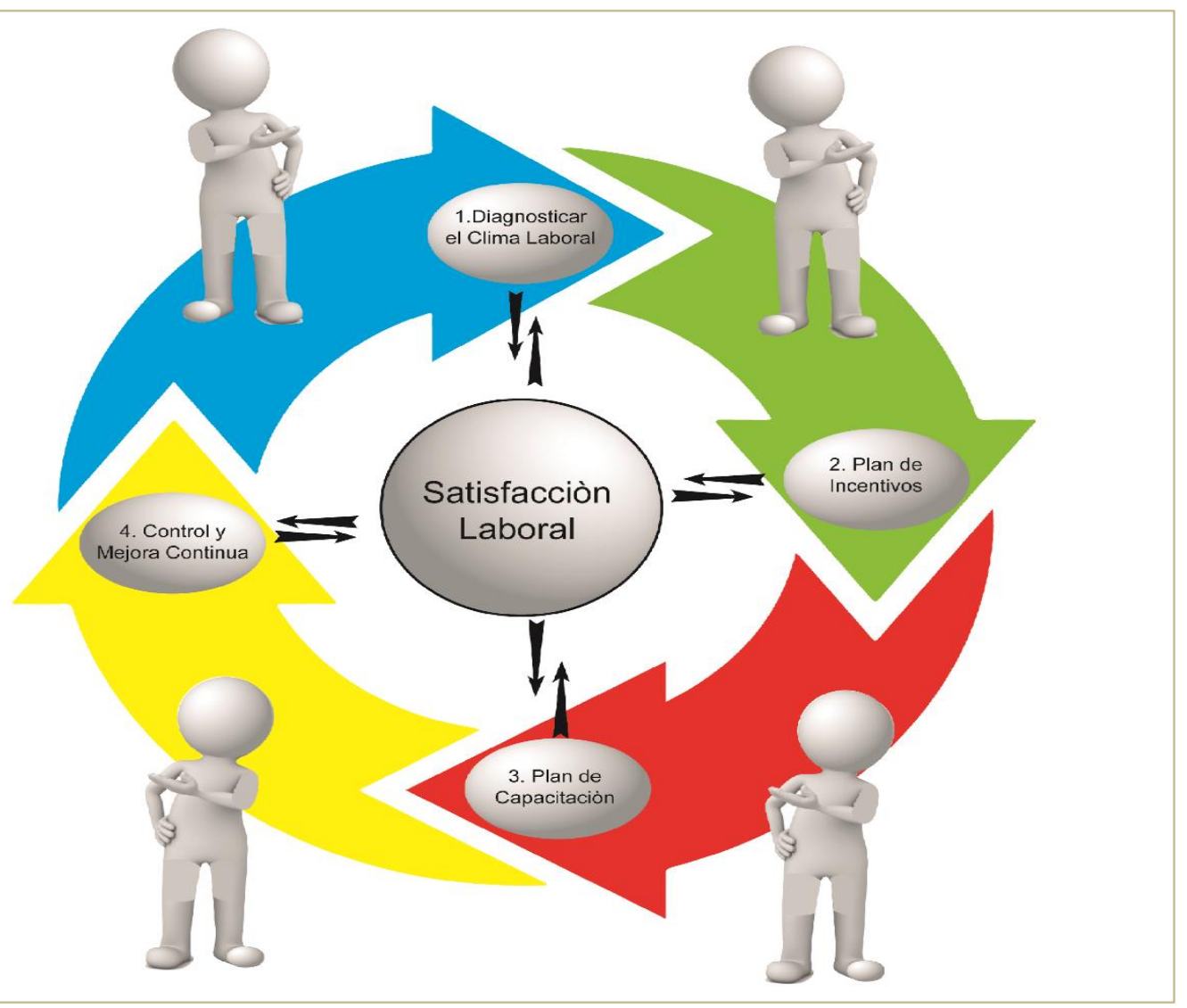

Fuente: Elaboración propia.

\section{Diagnosticar el Clima Laboral}

Con el fin de aportar a mejorar la insatisfacción laboral se ha realizara una encuesta para realizar el diagnóstico de la empresa Motricentro Cía. Ltda., la misma que se realizó a 47 empleados, fueron tabuladas, evaluadas, graficadas e interpretadas. 
Encuesta. - Es un conjunto de preguntas relacionadas a un tema específico que tiene como finalidad recolectar datos precisos que aportan a una investigación, los mismo que son fundamentales para la toma de decisiones. Aunque existen diversos modelos de encuesta, es fundamental que las preguntas se ajusten a la cultura y las dinámicas internas de la compañía. Algunos de los modelos de encuesta más comunes.

\section{Encuesta de Diagnostico Clima Laboral. Tabla 3.}

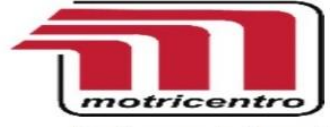

Por favor conteste confidencialmente las siguientes preguntas calificándolas del 1 al 5 , (1 es la calificación mínima y 5 es la calificación máxima)
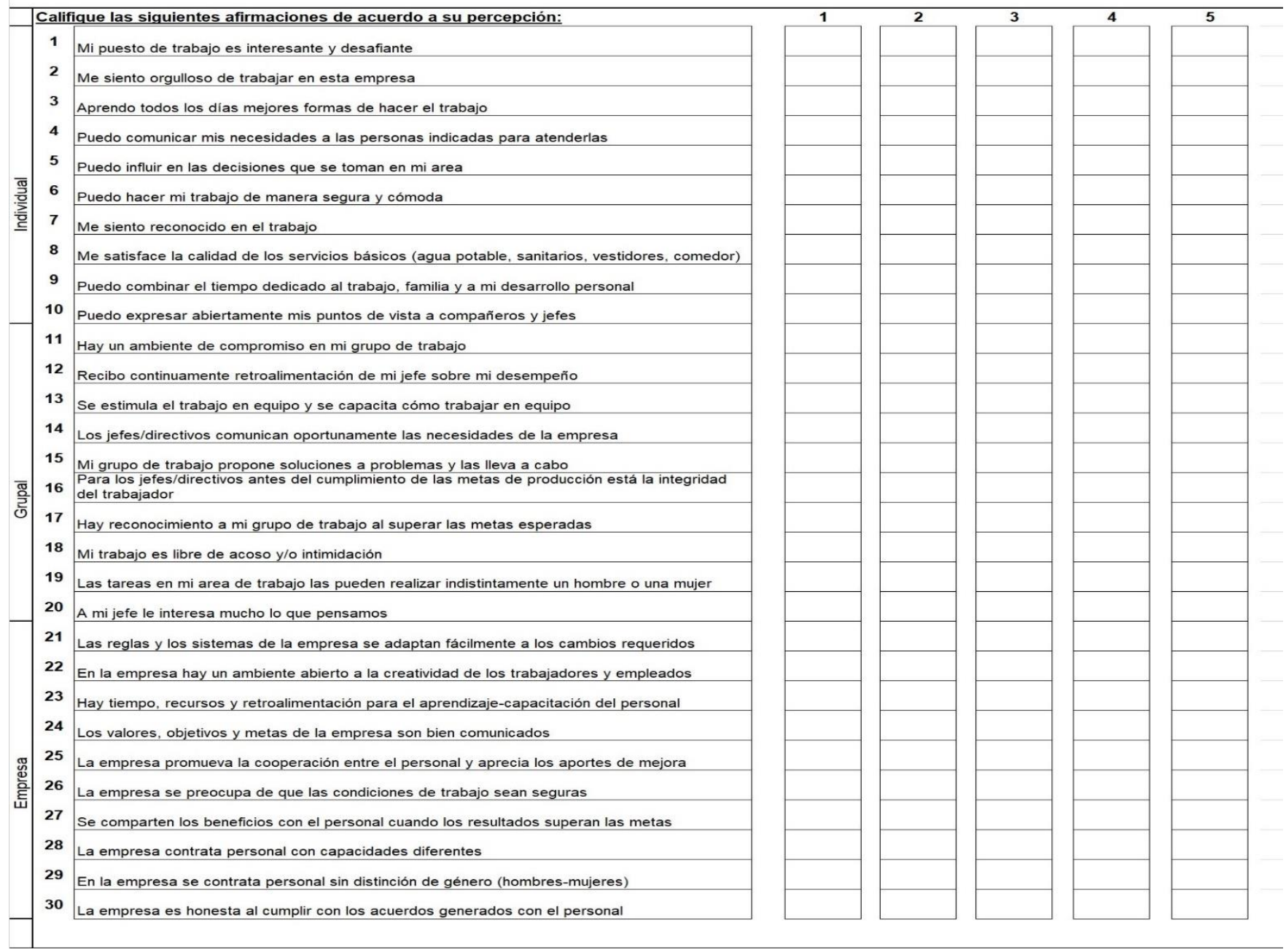

Fuente: Elaboración Propia. 


\section{Tabulación.}

Tabla 4.

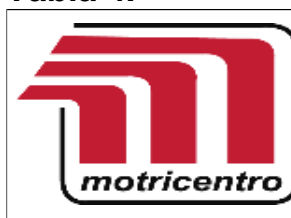

Empresa:

Motricentro Cia. Ltda.

Clima Laboral

Dirección:

Gil Ramirez Dávalos $14-34$ y Turuhuayco

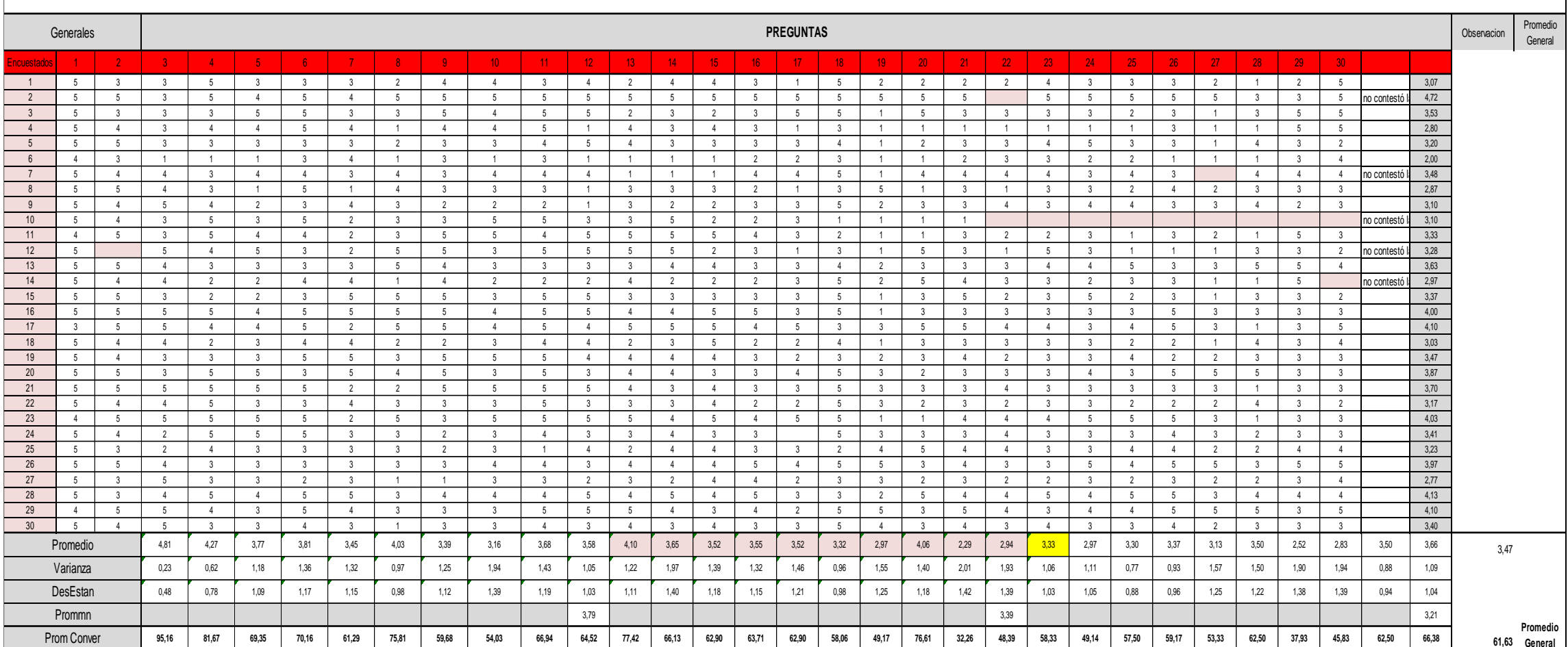

Fuente: Elaboración Propia. 
Revista Arbitrada Interdisciplinaria KOINONIA

Año IV. Vol IV. ํำ. Edición especial 2019

Hecho el depósito de Ley: FA2016000010 ISSN: 2542-3088

FUNDACIÓN KOINONIA (F.K). Santa Ana de Coro. Venezuela.

Clima Laboral.

Figura 4.

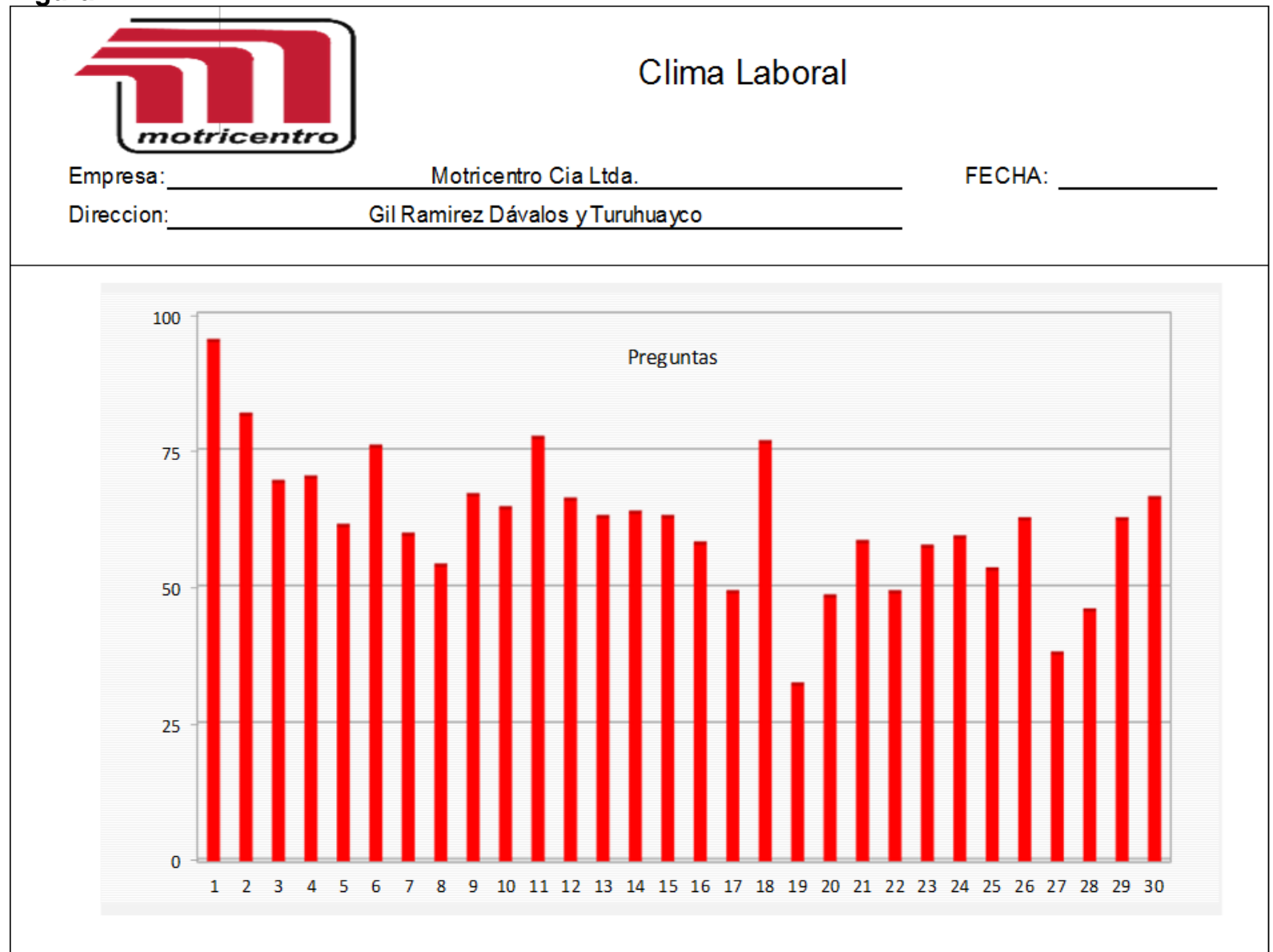

Fuente: Elaboración Propia.

Interpretación.

Tabla 5.

\begin{tabular}{|c|c|c|c|c|c|c|c|c|c|c|c|}
\hline \multirow{2}{*}{ Dimensión } & \multicolumn{2}{|c|}{ Productividad } & \multicolumn{8}{|c|}{ Trabajo } & \multirow[b]{2}{*}{ Promedio } \\
\hline & $\begin{array}{c}\text { Compromis } \\
0\end{array}$ & Motivación & Aprendizaje & $\begin{array}{c}\text { Comunicació } \\
n\end{array}$ & Participación & $\begin{array}{c}\text { Salud / } \\
\text { Seguridad }\end{array}$ & $\begin{array}{c}\text { Compensaci } \\
\text { ón }\end{array}$ & Bienestar & Género & Rel, Laboral & \\
\hline Individual & 95,16 & 81,67 & 69,35 & 70,16 & 61,29 & 75,81 & 59,68 & 54,03 & 66,94 & 64,52 & 69,86 \\
\hline Grupal & 77,42 & 66,13 & 62,90 & 63,71 & 62,90 & 58,06 & 49,17 & 76,61 & 32,26 & 48,39 & 59,76 \\
\hline Empresa & 58,33 & 49,14 & 57,50 & 59,17 & 53,33 & 62,50 & 37,93 & 45,83 & 62,50 & 66,38 & 55,26 \\
\hline TOTAL & 76,97 & 65,64 & 63,25 & 64,35 & 59,18 & 65,46 & 48,93 & 58,83 & 53,90 & 59,76 & 61,63 \\
\hline
\end{tabular}


Revista Arbitrada Interdisciplinaria KOINONIA

Año IV. Vol IV. №1. Edición especial 2019

Hecho el depósito de Ley: FA2016000010 ISSN: 2542-3088

FUNDACIÓN KOINONIA (F.K). Santa Ana de Coro. Venezuela.

Diana Elizabeth Valencia Naranjo; Juan Carlos Erazo Álvarez; Cecilia Ivonne Narváez Zurita

\section{Fuente: Elaboración Propia.}

Dimensiones.

Figura 5.

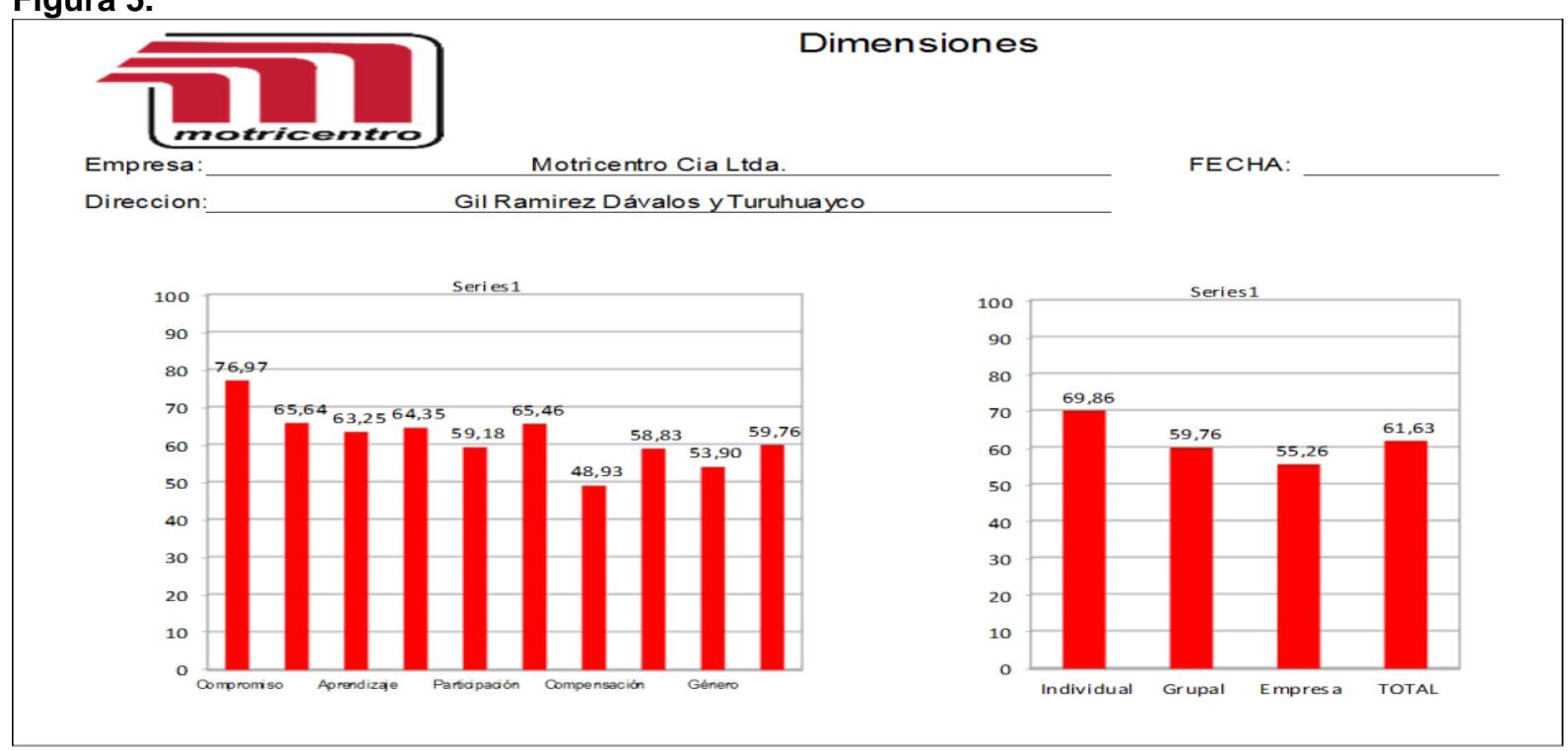

Interpretación.

Tabla 6. 
Revista Arbitrada Interdisciplinaria KOINONIA

Año IV. Vol IV. N¹. Edición especial 2019

Hecho el depósito de Ley: FA2016000010

ISSN: 2542-3088

FUNDACIÓN KOINONIA (F.K). Santa Ana de Coro. Venezuela.

Diana Elizabeth Valencia Naranjo; Juan Carlos Erazo Álvarez; Cecilia Ivonne Narváez Zurita

\begin{tabular}{|c|c|}
\hline 1 & Mi puesto de trabajo es interesante y desafiante \\
\hline 2 & Me siento orgulloso de trabajar en esta empresa \\
\hline 3 & Aprendo todos los días mejores formas de hacer el trabajo \\
\hline 4 & Puedo comunicar mis necesidades a las personas indicadas para atenderlas \\
\hline 5 & Puedo influir en las decisiones que se toman en mi area \\
\hline 6 & Puedo hacer mi trabajo de manera segura y cómoda \\
\hline 7 & Me siento reconocido en el trabajo \\
\hline 8 & Me satisface la calidad de los servicios básicos (agua potable, sanitarios, vestidores, comedor) \\
\hline 9 & Puedo combinar el tiempo dedicado al trabajo, familia y a mi desarrollo personal \\
\hline 10 & Puedo expresar abiertamente mis puntos de vista a compañeros y jefes \\
\hline 11 & Hay un ambiente de compromiso en mi grupo de trabajo \\
\hline 12 & Recibo continuamente retroalimentación de mi jefe sobre mi desempeño \\
\hline 13 & Se estimula el trabajo en equipo y se capacita cómo trabajar en equipo \\
\hline 14 & Los jefes/directivos comunican oportunamente las necesidades de la empresa \\
\hline 15 & Mi grupo de trabajo propone soluciones a problemas y las lleva a cabo \\
\hline 16 & $\begin{array}{l}\text { Para los jefes/directivos antes del cumplimiento de las metas de producción está la integridad } \\
\text { del trabajador }\end{array}$ \\
\hline 17 & Hay reconocimiento a mi grupo de trabajo al superar las metas esperadas \\
\hline 18 & Mi trabajo es libre de acoso y/o intimidación \\
\hline 19 & Las tareas en mi area de trabajo las pueden realizar indistintamente un hombre o una mujer \\
\hline 20 & A mi jefe le interesa mucho lo que pensamos \\
\hline 21 & Las reglas y los sistemas de la empresa se adaptan fácilmente a los cambios requeridos \\
\hline 22 & En la empresa hay un ambiente abierto a la creatividad de los trabajadores y empleados \\
\hline 23 & Hay tiempo, recursos y retroalimentación para el aprendizaje-capacitación del personal \\
\hline 24 & Los valores, objetivos y metas de la empresa son bien comunicados \\
\hline 25 & La empresa promueva la cooperación entre el personal y aprecia los aportes de mejora \\
\hline 26 & La empresa se preocupa de que las condiciones de trabajo sean seguras \\
\hline 27 & Se comparten los beneficios con el personal cuando los resultados superan las metas \\
\hline 28 & La empresa contrata personal con capacidades diferentes \\
\hline 29 & En la empresa se contrata personal sin distinción de género (hombres-mujeres) \\
\hline 30 & La empresa es honesta al cumplir con los acuerdos generados con el personal \\
\hline
\end{tabular}

Fortalezas y Debilidades.

Figura 6. 
Revista Arbitrada Interdisciplinaria KOINONIA

Año IV. Vol IV. N${ }^{\circ}$. Edición especial 2019

Hecho el depósito de Ley: FA2016000010 ISSN: 2542-3088

FUNDACIÓN KOINONIA (F.K). Santa Ana de Coro. Venezuela.

Diana Elizabeth Valencia Naranjo; Juan Carlos Erazo Álvarez; Cecilia Ivonne Narváez Zurita

\section{Fortalezas y Debilidades}

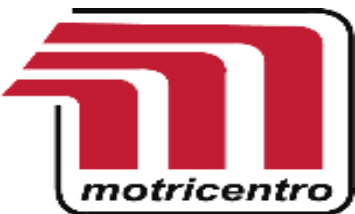

Empresa:

Direccion:
Motricentro Cia Ltda.

Gil Ramirez Dávalos y Turuhuayco
FECHA:

\section{Fortalezas}

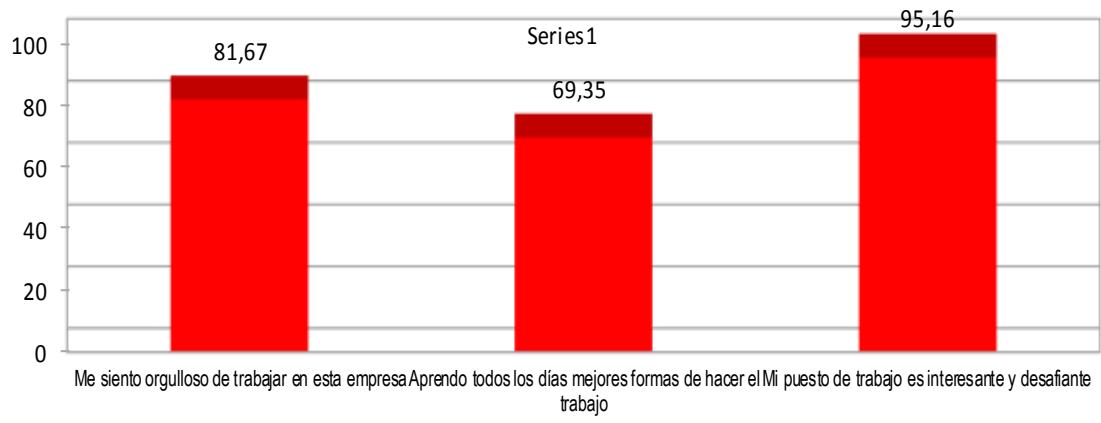

Debilidades

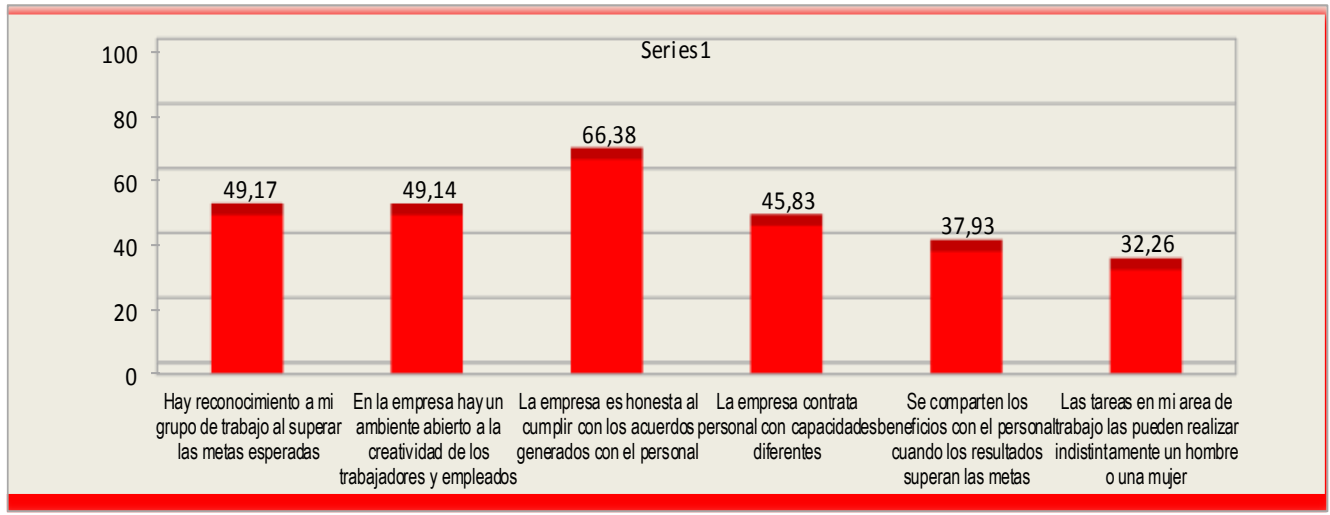




\section{2.- Plan de Incentivos}

\begin{tabular}{|c|c|c|}
\hline \multicolumn{3}{|c|}{ Plan de Incentivos } \\
\hline \multicolumn{3}{|c|}{ Incentivos Genarales } \\
\hline $\begin{array}{c}\text { Incentivo a } \\
\text { aplicar }\end{array}$ & Actividad & Descripción \\
\hline Indirecto Positivo & Cumpleaños & $\begin{array}{c}\text { Dar al trabajador felicitaciones por su cumpleaños, } \\
\text { con fases de motivación y agradecimiento, en las } \\
\text { redes sociales de la empresa. }\end{array}$ \\
\hline \multicolumn{2}{|c|}{ Presupuesto: } & $\$ 1$ \\
\hline \multicolumn{3}{|c|}{ Objetivo: Festejar al trabajador en un día especial para ellos. } \\
\hline \multicolumn{3}{|c|}{ Responsables: Talento Humano- Gerencia- Presidencia. } \\
\hline $\begin{array}{c}\text { Incentivo a } \\
\text { aplicar }\end{array}$ & Actividad & Descripción \\
\hline Indirecto Positivo & $\begin{array}{l}\text { Día del amor y la } \\
\text { amistad }\end{array}$ & $\begin{array}{l}\text { Realizar un agasajo a los trabajadores dentro de la } \\
\text { empresa (2horas) y dar un presente por festejar el } \\
\text { día. }\end{array}$ \\
\hline \multicolumn{2}{|c|}{ Presupuesto: } & $\$ 150$ \\
\hline \multicolumn{3}{|c|}{ Objetivo: Fortalecer lazos de amistad entre todo el personal y con la organización. } \\
\hline \multicolumn{3}{|c|}{ Responsables: Talento Humano- Gerencia- Presidencia. } \\
\hline $\begin{array}{c}\text { Incentivo a } \\
\text { aplicar }\end{array}$ & Actividad & Descripción \\
\hline Indirecto Positivo & Día del trabajo & $\begin{array}{l}\text { Actividad recreativa fuera de la empresa (juegos } \\
\text { deportivos, dinámicas, premiaciones.) }\end{array}$ \\
\hline \multicolumn{2}{|c|}{ Presupuesto: } & $\$ 700$ \\
\hline \multicolumn{3}{|c|}{ Objetivo: Estimular el trabajo en equipo con todos los trabajadores. } \\
\hline \multicolumn{3}{|c|}{ Responsables: Talento Humano- Gerencia- Presidencia. } \\
\hline $\begin{array}{c}\text { Incentivo a } \\
\text { aplicar }\end{array}$ & Actividad & Descripción \\
\hline Indirecto Positivo & Día de la familia & $\begin{array}{c}\text { Actividad recreativa fuera de la empresa (juegos } \\
\text { deportivos, dinámicas grupales e individuales. } \\
\text { premiaciones.) }\end{array}$ \\
\hline \multicolumn{2}{|c|}{ Presupuesto: } & $\$ 900$ \\
\hline \multicolumn{3}{|c|}{ Objetivo: Reconocer el valor significativo de la familia del trabajador en la empresa } \\
\hline \multicolumn{3}{|c|}{ Responsables: Talento Humano- Gerencia- Presidencia. } \\
\hline
\end{tabular}

Continua 
Revista Arbitrada Interdisciplinaria KOINONIA

Año IV. Vol IV. N¹. Edición especial 2019

Hecho el depósito de Ley: FA2016000010 ISSN: 2542-3088

FUNDACIÓN KOINONIA (F.K). Santa Ana de Coro. Venezuela.

Diana Elizabeth Valencia Naranjo; Juan Carlos Erazo Álvarez; Cecilia Ivonne Narváez Zurita

\begin{tabular}{|c|c|c|}
\hline \multicolumn{3}{|c|}{ Plan de Incentivos } \\
\hline \multicolumn{3}{|c|}{ Incentivos Genarales } \\
\hline $\begin{array}{c}\text { Incentivo a } \\
\text { aplicar }\end{array}$ & Actividad & Descripción \\
\hline Indirecto Positivo & Día del niño & $\begin{array}{c}\text { Salida de campo con los hijos de los trabajadores } \\
\text { por un día (juegos deportivos, dinámicas grupales, } \\
\text { premiaciones.) }\end{array}$ \\
\hline \multicolumn{2}{|c|}{$\begin{array}{l}\text { Presupuesto: } \\
\end{array}$} & $\$ 400$ \\
\hline \multicolumn{3}{|c|}{ Objetivo: Reconocer el valor significativo de la familia del trabajador en la empresa } \\
\hline \multicolumn{3}{|c|}{ Responsables: Talento Humano- Gerencia- Presidencia. } \\
\hline $\begin{array}{c}\text { Incentivo a } \\
\text { aplicar }\end{array}$ & Actividad & Descripción \\
\hline Indirecto Positivo & $\begin{array}{c}\text { Día de la madre Día } \\
\text { del padre Día de la } \\
\text { mujer }\end{array}$ & Dar al trabajador un presente por festejar su día. \\
\hline \multicolumn{2}{|c|}{ Presupuesto: } & $\$ 600$ \\
\hline \multicolumn{3}{|c|}{ Objetivo: Festejar al trabajador en un día especial para ellos. } \\
\hline \multicolumn{3}{|c|}{ Responsables: Talento Humano- Gerencia- Presidencia. } \\
\hline
\end{tabular}


Revista Arbitrada Interdisciplinaria KOINONIA

Año IV. Vol IV. N 1 . Edición especial 2019

Hecho el depósito de Ley: FA2016000010 ISSN: 2542-3088

FUNDACIÓN KOINONIA (F.K). Santa Ana de Coro. Venezuela.

Diana Elizabeth Valencia Naranjo; Juan Carlos Erazo Álvarez; Cecilia Ivonne Narváez Zurita

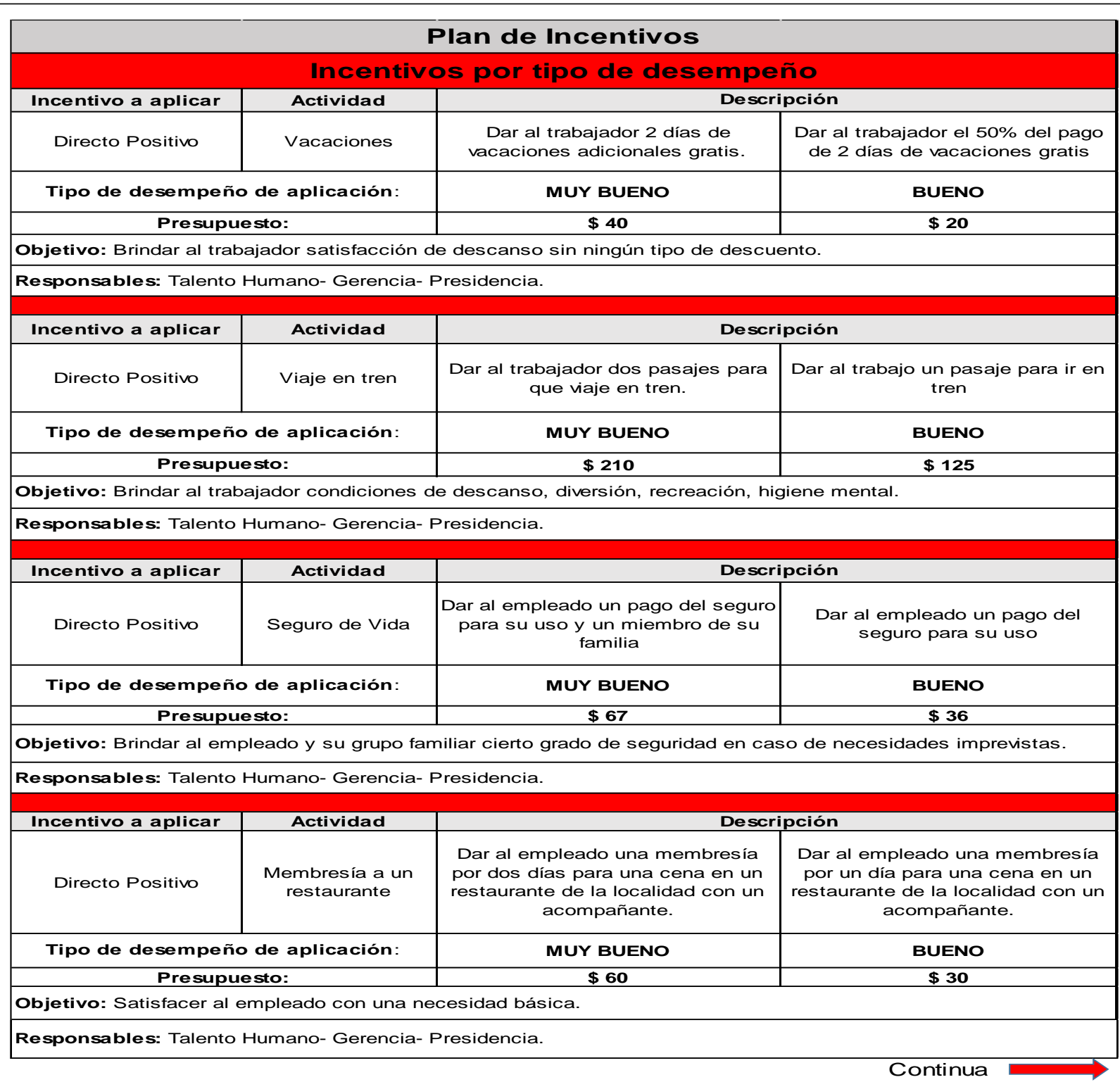




\begin{tabular}{|c|c|c|c|}
\hline & & lan de Incentivo & \\
\hline & Incentiv & s por tipo de de: & \\
\hline Incentivo a aplicar & Actividad & & \\
\hline Indirecto Positivo & $\begin{array}{l}\text { Reconocimiento en } \\
\text { redes sociales }\end{array}$ & $\begin{array}{r}\text { Se reconocerá al trabaja } \\
\text { alc }\end{array}$ & a empresa por logros \\
\hline Tipo de desempe & o de aplicación: & MUY BUENO & BUENO \\
\hline Presup & iesto: & $\$ 30$ & $\$ 15$ \\
\hline Objetivo: Tomar como & ejemplo el rendimient & del trabajador como moti & añeros. \\
\hline Responsables: Talent & Humano- Gerencia- & esidencia. & \\
\hline Incentivo a aplicar & Actividad & & \\
\hline Directo Positivo & Parqueadero & $\begin{array}{r}\text { Facilitar al empleado u } \\
\text { empre }\end{array}$ & $\begin{array}{l}\text { miento dado que la } \\
\text { ico }\end{array}$ \\
\hline Tipo de desempe & o de aplicación: & MUY BUENO & BUENO \\
\hline Presup & esto: & & \\
\hline Objetivo: Motivar al er & pleado y conseguir $\mathrm{m}$ & yor compromiso en sus a & \\
\hline Responsables: Talent & Humano- Gerencia- & esidencia. & \\
\hline Incentivo a aplicar & Actividad & & \\
\hline Directo Positivo & Entradas al cine & Obsequiar entradas al & 3 miembros de su \\
\hline Tipo de desempe & o de aplicación: & MUY BUENO & BUENO \\
\hline Presup & esto: & & \\
\hline
\end{tabular}

Objetivo: Brindar al trabajador una actividad extra laboral con la cual aumente su compromiso laboral con la empresa.

Responsables: Talento Humano- Gerencia- Presidencia.

\begin{tabular}{|c|c|c|c|}
\hline Incentivo a aplicar & Actividad & \multicolumn{2}{|c|}{ Descripción } \\
\hline Directo Positivo & $\begin{array}{c}\text { Bono punto de } \\
\text { venta }\end{array}$ & $\begin{array}{l}\text { Dar un bono \$30 en la sucursal que } \\
\text { mas ventas tenga al mes destinado } \\
\text { al mejor vendedor }\end{array}$ & $\begin{array}{l}\text { Dar un bono \$20 en la sucursal } \\
\text { que mas ventas tenga al mes } \\
\text { destinado al mejor vendedor }\end{array}$ \\
\hline Tipo de desempeño de aplicación: & MUY BUENO & BUENO \\
\hline \multicolumn{2}{|c|}{ Presupuesto: } & $\mathbf{\$ 3 0}$ & $\mathbf{\$ 2 0}$ \\
\hline
\end{tabular}

Objetivo: Fortalecer la identidad corporativa del empleado en la organización. 


\begin{tabular}{|c|c|c|c|}
\hline \multicolumn{4}{|c|}{ Plan de Incentivos } \\
\hline \multicolumn{4}{|c|}{ Incentivos por tipo de desempeño } \\
\hline Incentivo a aplicar & Actividad & \multicolumn{2}{|c|}{ Descripción } \\
\hline Indirecto Positivo & Formación. & \multicolumn{2}{|c|}{ Dar al trabajador una capacitación de su interés. } \\
\hline \multicolumn{2}{|c|}{ Tipo de desempeño de aplicación: } & MUY BUENO & BUENO \\
\hline \multicolumn{2}{|c|}{ Presupuesto: } & \multicolumn{2}{|c|}{$\$ 175$} \\
\hline \multicolumn{4}{|c|}{ Objetivo: Apoyar al trabajador en sus conocimientos y habilidades necesarias para el desarrollo de sus actividades. } \\
\hline \multicolumn{4}{|c|}{ Responsables: Talento Humano- Gerencia- Presidencia. } \\
\hline Incentivo a aplicar & Actividad & \multicolumn{2}{|c|}{ Descripción } \\
\hline Indirecto Positivo & Grupos de Mejora. & \multicolumn{2}{|c|}{$\begin{array}{l}\text { Proponer un tema de proyecto para su grupo de mejora, mencionando } \\
\text { los objetivos, la meta. }\end{array}$} \\
\hline \multicolumn{2}{|c|}{ Tipo de desempeño de aplicación: } & MUY BUENO & BUENO \\
\hline \multicolumn{2}{|c|}{ Presupuesto: } & \multicolumn{2}{|c|}{ No aplica } \\
\hline \multicolumn{4}{|c|}{ Objetivo: Aumentar el compromiso del trabajador con la empresa. } \\
\hline \multicolumn{4}{|c|}{ Responsables: Talento Humano- Gerencia- Presidencia- Líder del Grupo de mejora. } \\
\hline Incentivo a aplicar & Actividad & \multicolumn{2}{|c|}{ Descripción } \\
\hline Indirecto Positivo & Reinducciones & \multicolumn{2}{|c|}{$\begin{array}{l}\text { Explicar al trabajador cuidadosamente las actividades que tiene que } \\
\text { realizar en su puesto de trabajo }\end{array}$} \\
\hline \multicolumn{2}{|c|}{ Tipo de desempeño de aplicación: } & MUY BUENO & BUENO \\
\hline \multicolumn{2}{|c|}{ Presupuesto: } & \multicolumn{2}{|c|}{ No aplica } \\
\hline \multicolumn{4}{|c|}{ Objetivo: Aumentar el nivel de conocimiento de los trabajadores en el puesto de trabajo. } \\
\hline \multicolumn{4}{|c|}{ Responsables: Talento Humano- Gerencia- Presidencia- Jefe inmediato. } \\
\hline Incentivo a aplicar & Actividad & \multicolumn{2}{|c|}{ Descripción } \\
\hline Indirecto Positivo & Capacitación & \multicolumn{2}{|c|}{ Capacitaciones para las oportunidades de mejora del trabajador. } \\
\hline \multicolumn{2}{|c|}{ Tipo de desempeño de aplicación: } & MUY BUENO & BUENO \\
\hline \multicolumn{2}{|c|}{ Presupuesto: } & \multicolumn{2}{|c|}{ No aplica } \\
\hline \multicolumn{4}{|c|}{ Objetivo: Aumentar el nivel de conocimiento de los trabajadores en el puesto de trabajo. } \\
\hline Responsables: Talent & tumano- Gerencia- & esidencia. & \\
\hline
\end{tabular}


Revista Arbitrada Interdisciplinaria KOINONIA

Año IV. Vol IV. N 1 . Edición especial 2019

Hecho el depósito de Ley: FA2016000010 ISSN: $2542-3088$

FUNDACIÓN KOINONIA (F.K). Santa Ana de Coro. Venezuela.

Diana Elizabeth Valencia Naranjo; Juan Carlos Erazo Álvarez; Cecilia Ivonne Narváez Zurita

\begin{tabular}{|c|c|c|c|}
\hline \multicolumn{3}{|c|}{ Plan de Incentivos } \\
\hline Incentivos por tipo de desempeño \\
\hline Directo Positivo & Bono Eficiencia & Se brindara al empleado un bono de 50 dólares mensuales. \\
\hline Tipo de desempeño de aplicación: & MUY BUENO & BUENO \\
\hline \multicolumn{3}{|c|}{ Presupuesto: } & $\mathbf{5 0}$ \\
\hline Objetivo: Premiar al trabajador por su eficiencia en las actividades que realiza. \\
\hline Responsables: Talento Humano- Gerencia- Presidencia. \\
\hline
\end{tabular}


Revista Arbitrada Interdisciplinaria KOINONIA

Año IV. Vol IV. N 1 . Edición especial 2019

Hecho el depósito de Ley: FA2016000010 ISSN: 2542-3088

FUNDACIÓN KOINONIA (F.K). Santa Ana de Coro. Venezuela.

Diana Elizabeth Valencia Naranjo; Juan Carlos Erazo Álvarez; Cecilia Ivonne Narváez Zurita

\begin{tabular}{|c|c|c|c|c|c|}
\hline \multicolumn{6}{|c|}{ Plan de Incentivos } \\
\hline \multicolumn{6}{|c|}{ Incentivos por Metas } \\
\hline $\begin{array}{c}\text { Incentivo a } \\
\text { aplicar }\end{array}$ & Actividad & Departamento & Indicador & $\begin{array}{c}\text { Límites de } \\
\text { control }\end{array}$ & Descripción \\
\hline $\begin{array}{l}\text { Directo } \\
\text { Positivo }\end{array}$ & Bono & $\begin{array}{l}\text { Talento } \\
\text { humano }\end{array}$ & $\begin{array}{c}\text { Rotacion de Personal } \\
\text { l=(\# de personal que ha } \\
\text { salido/l=(\# de personal que ha } \\
\text { salido/ }\end{array}$ & $1 \%-3 \%$ & $\begin{array}{l}\text { Bono de } \$ 30.00 \text { dólares } \\
\text { si se mantienen en ese } \\
\text { rango de porcentaje de } \\
\text { rotación de personal. }\end{array}$ \\
\hline $\begin{array}{l}\text { Directo } \\
\text { Positivo }\end{array}$ & Bono & $\begin{array}{c}\text { Almacenamient } \\
\text { o y Logística }\end{array}$ & $\begin{array}{l}\text { Errores en despachos } \\
\mathrm{I}=(\text { Despachos con errores } \\
\text { /Total de despachos })^{\star} 100\end{array}$ & $0.4 \%-0.6 \%$ & $\begin{array}{l}\text { Se proporcionará } \$ 45 \\
\text { dólares si no pasa las } \\
\text { devoluciones del } 0.6 \%\end{array}$ \\
\hline \multirow{2}{*}{$\begin{array}{l}\text { Directo } \\
\text { Positivo }\end{array}$} & \multirow[b]{2}{*}{ Bono } & \multirow[b]{2}{*}{ Ventas } & $\begin{array}{c}\text { Recaudación } \\
\mathrm{I}=\text { Total de cartera } \\
\text { recaudada/Total de Cartera }\end{array}$ & $55 \%-65 \%$ & $\begin{array}{c}\text { Se proporcionará } \$ 120 \\
\text { dólares si sobrepasa el } \\
65 \%\end{array}$ \\
\hline & & & $\begin{array}{c}\text { Cartera Vencida } \\
\mathrm{I}=\text { Total de cartera vencida/ } \\
\text { Total de cartera }\end{array}$ & $5 \%-10 \%$ & $\begin{array}{c}\text { Se proporcionará } \$ 120 \\
\text { dólares si se mantiene } \\
\text { en el } 5 \%\end{array}$ \\
\hline $\begin{array}{l}\text { Directo } \\
\text { Positivo }\end{array}$ & Bono & $\begin{array}{l}\text { Control De } \\
\text { Calidad }\end{array}$ & $\begin{array}{l}\text { Devolución por calidad } \\
\text { I= Devueltos por mal despacho } \\
\text { / despachados }{ }^{\star} 100\end{array}$ & $\begin{array}{l}F=0.1 \%-0.5 \% \\
V=0.1 \%-0.5 \% \\
H=0.1 \%-0.5 \%\end{array}$ & $\begin{array}{c}\text { Se proporcionará } \$ 10 \\
\text { dólares si no sobrepasa } \\
\text { el } 0.5 \% \text {. }\end{array}$ \\
\hline $\begin{array}{l}\text { Directo } \\
\text { Positivo }\end{array}$ & Bono & Compras & $\begin{array}{l}\text { Compras que cumplen con } \\
\text { requerimiento } \\
\text { I= (Ítems comprados perfectas } \\
\text { condiciones/ Total de ítems } \\
\text { comprados en el mes)*100 }\end{array}$ & $85 \%-95 \%$ & $\begin{array}{c}\text { Se proporcionará \$30 } \\
\text { dólares si sobrepasa el } \\
95 \% .\end{array}$ \\
\hline $\begin{array}{l}\text { Directo } \\
\text { Positivo }\end{array}$ & Bono & Finanzas & $\begin{array}{l}\text { Cumplimiento de Finanzas } \\
\text { Presupuesto }=\text { (Gastos } \\
\text { realizados/Presupuesto de } \\
\text { gastos) * } 100 \\
\text { I= (inversiones } \\
\text { realizados/Presupuesto de } \\
\text { inversiones) * } 100 \\
\end{array}$ & $95 \%-100 \%$ & $\begin{array}{c}\text { Si se mantiene entre el } \\
95 \% \text { y } 100 \% \text { se } \\
\text { proporcionará un bono } \\
\text { de } \$ 30 \text { dólares. }\end{array}$ \\
\hline $\begin{array}{l}\text { Directo } \\
\text { Positivo }\end{array}$ & Bono & $\begin{array}{l}\text { Gerencia } \\
\text { Ventas }\end{array}$ & $\begin{array}{l}\text { Requerimientos Cumplidos } \\
\mathrm{I}=\text { (\# de peticiones cumplidas } / \# \\
\text { de peticiones receptadas) } * 100\end{array}$ & $85 \%-100 \%$ & $\begin{array}{l}\text { Si se mantiene entre el } \\
95 \% \text { y } 100 \% \text { se } \\
\text { proporcionará un bono } \\
\text { de } \$ 30 \text { dólares. }\end{array}$ \\
\hline \multicolumn{2}{|c|}{$\begin{array}{l}\text { Tipo de } \\
\text { desempeño }\end{array}$} & \multicolumn{4}{|c|}{ MUY BUENO Y BUENO } \\
\hline \multicolumn{6}{|c|}{ Objetivo: Recompensar al trabajador por su trabajo, y las metas alcanzadas. } \\
\hline Responsa & Talento & mano- Geren & ia- Presidencia. & & \\
\hline
\end{tabular}

\section{3.- Plan de Capacitación}


Revista Arbitrada Interdisciplinaria KOINONIA

Año IV. Vol IV. N 1 . Edición especial 2019

Hecho el depósito de Ley: FA2016000010 ISSN: 2542-3088

FUNDACIÓN KOINONIA (F.K). Santa Ana de Coro. Venezuela.

Diana Elizabeth Valencia Naranjo; Juan Carlos Erazo Álvarez; Cecilia Ivonne Narváez Zurita

\section{Plan de Capacitacion}

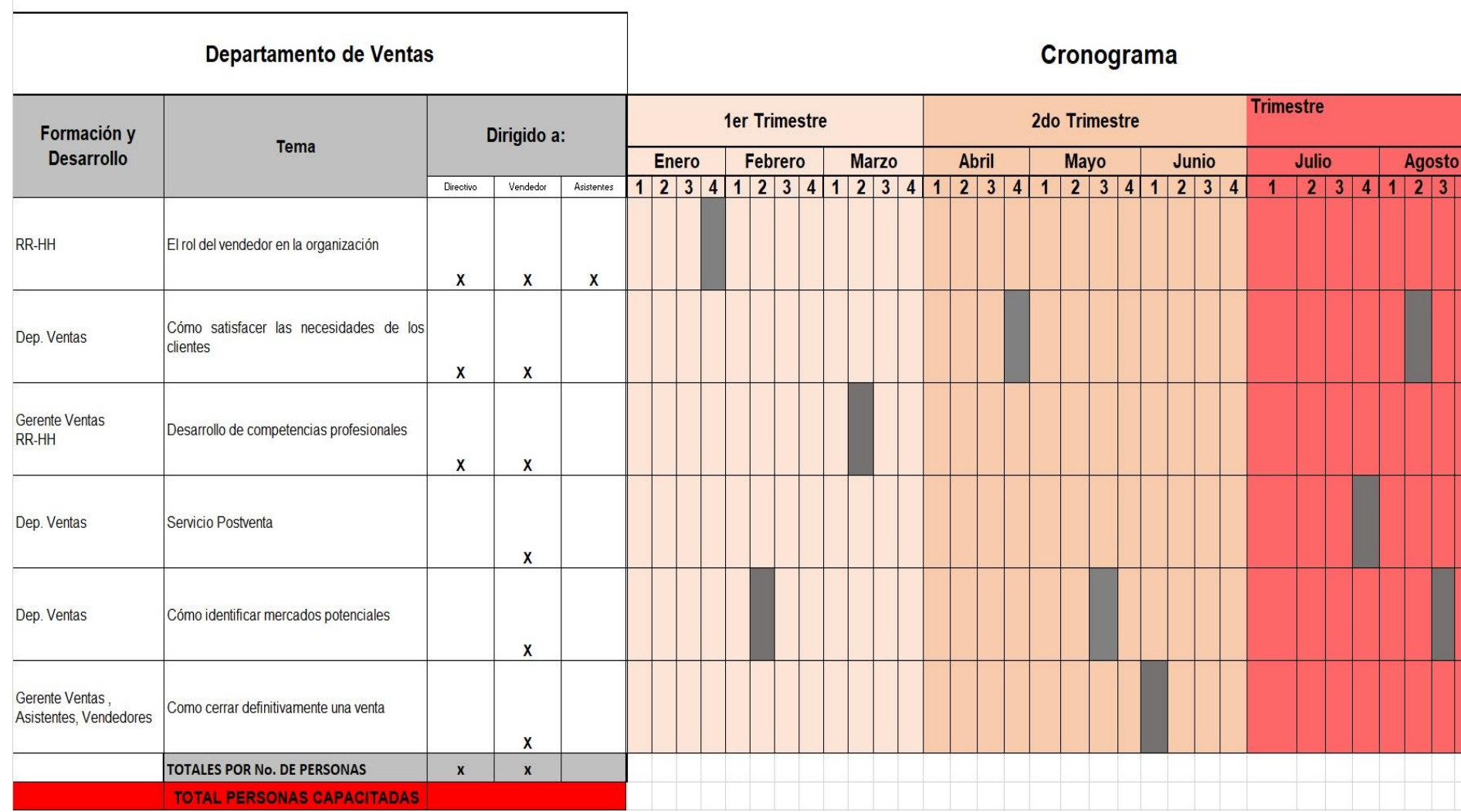


Revista Arbitrada Interdisciplinaria KOINONIA

Año IV. Vol IV. N¹. Edición especial 2019

Hecho el depósito de Ley: FA2016000010

ISSN: 2542-3088

FUNDACIÓN KOINONIA (F.K). Santa Ana de Coro. Venezuela.

\section{Control y mejora continúa}

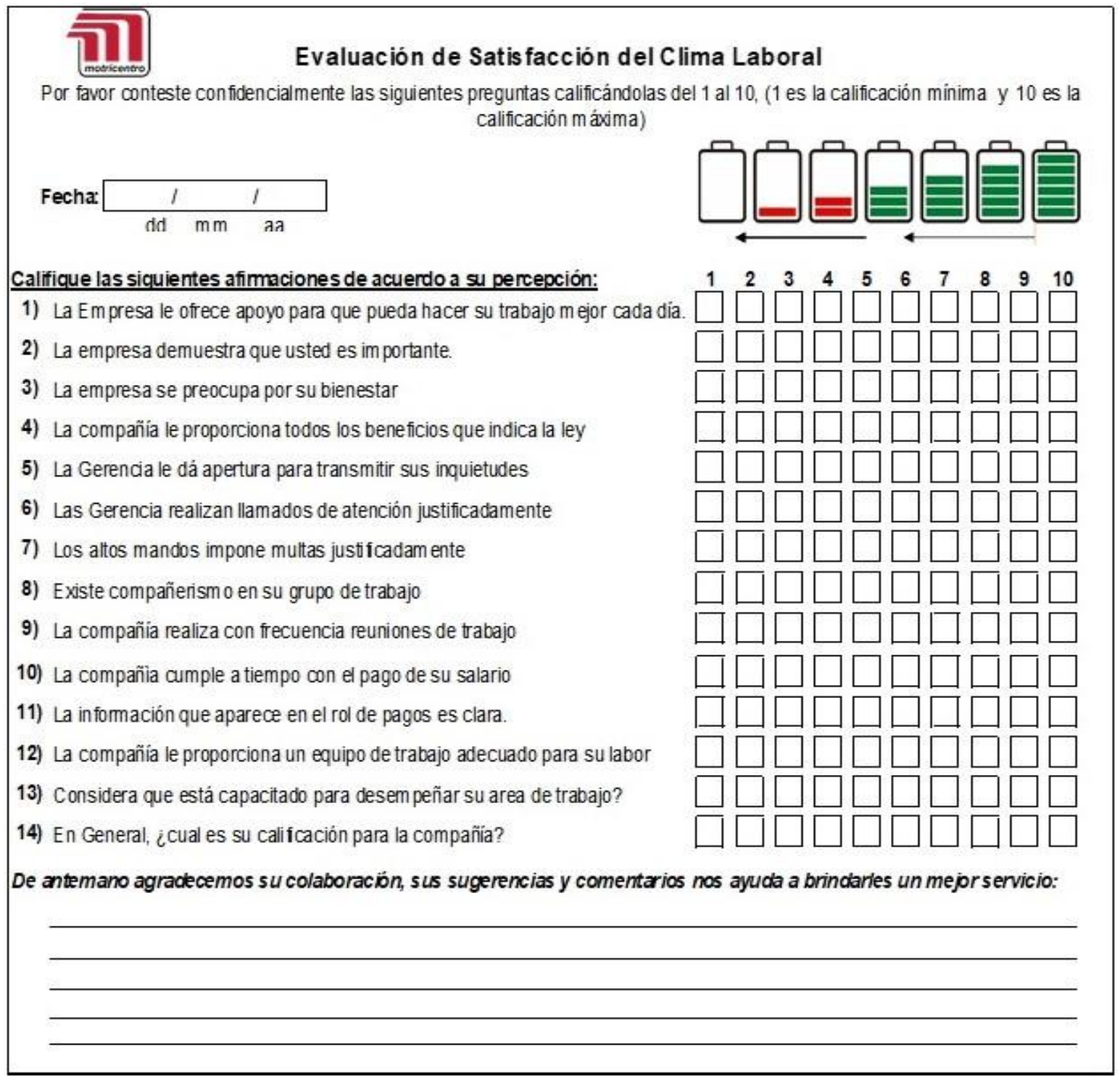




\section{DISCUSIÓN}

Es necesario recordar que el departamento de talento humano no ha realizado los programas de clima laboral y motivación por lo que se requiere realizar una política para que sea aplicado de forma constante y permanente, el panorama no parecía del todo prometedor, a pesar de la excelente disposición por parte de la organización y agentes clave. Sin embargo, los objetivos específicos de la investigación poco a poco se fueron cumpliendo a cabalidad y en virtud de aquello, concuerdo profundamente con lo que plantea (Dick, 2000), "una buena investigación está diseñada para adaptarse a los intereses y habilidades de los participantes". Esto desembocó en un trabajo, tanto para definir y describir teóricamente algunas temáticas, como para profundizar y levantar información necesaria y clave para realizar la investigación y proponer una propuesta resolutiva; además de conocer el sistema actual de remuneraciones de la fuerza de ventas en la organización, debido a que esto permitía indagar más profundamente en los intereses y necesidades de los vendedores en cuestión.

A pesar de que Motricentro Cía. Ltda., es una empresa que ha desarrollado y comercializado variados proyectos a lo largo del país, sigue siendo una organización de pequeña estructura. Esto favoreció profundamente al momento de realizar la investigación, dado que el acceso fue más rápido de lo esperado y sin mayores inconvenientes. El bajo número de colaboradores en la organización tuvo por consecuencia una expansión más eficiente de la información con relación al proyecto, por cuanto las ideas y mejoras fueron bien recibidas, valoradas y criticadas de manera constructiva. Finalmente, en conjunto se creó este plan de incentivos y recompensas, el cual efectivamente comenzó su puesta en marcha desde enero de 2017. En este caso, la cantidad de empleados, el acceso a la información, los agentes clave, el rol de cada individuo en su ocupación y el contexto organizacional, se combinaron de manera equilibrada, dando un resultado positivo en relación a las expectativas de la organización y objetivos de esta investigación. Todo lo anterior coincide, indudablemente, con los valores que caracterizan a esta organización (confianza, responsabilidad, eficiencia y flexibilidad), siendo prueba concreta no solo la 
experiencia en mi rol como investigador, sino en las propias entrevistas proporcionadas por los agentes clave dentro de la organización

\section{REFERENCIAS CONSULTADAS}

1. Aldana, J., \& Piña, J. (2017). Calidad del servicio prestado al cliente por los instructores de gimnasios. Revista Arbitrada Interdisciplinaria Koinonía, 2(3), 172-197. Recuperado de http://fundacionkoinonia.com.ve/ojs/index.php/revistakoinonia/article/view/59/46

2. Ivarez, L., Izquierdo, L., Gudiño, L., \& Macias, M. (2018). Coaching educativo: desarrollo de competencias en el educando de nivel superior. INNOVA Research Journal, 3(11), 169-182.

3. Alvarez, L., Izquierdo, L., Gudiño, L., \& Macias, M. (2018). Coaching educativo: desarrollo de competencias en el educando de nivel superior. INNOVA Research Journal, 3(11), 169-182.

4. ASESCO. (6 de 2018). Asociación española de Coaching. Obtenido de http://www.asescoaching.org/el-coaching/

5. Banco Central del Ecuador. (1 de Enero de 2015). Banco Central del EcuadorEstadísticas. Obtenido de Banco Central del Ecuador- Estadísticas: https://contenido.bce.fin.ec/documentos/Estadisticas/SectorReal/CuentasProvinciales/Indicep.htm

6. CB Biblián. (2019). Informe 2019. CB Biblián, 2.

7. Cuadri, J., Fierro, S., \& Palma, I. (2015). El coaching. Revista de Educación, Motricidad e Investigación, 1(4), 18-33.

8. Del Río, J., López, N., \& Rodríguez, C. (2015). Coaching: Concepciones diferentes desde las tipologías. Agunkuya, 5(2), 21-28.

9. Dick, B. (2000). Investigación en acción. En B. Dick, Investigación en acción.

10. EEC. (08 de 2019). Escuela Coaching. Obtenido de https://www.escuelacoaching.com/

11. ICF. (04 de 2017). ICF. Obtenido de https://coachfederation.org/ 
12. Leal, M., Mejías, L., \& Guédez, M. (2017). Coaching ontológico como enfoque gerencial, para la transformación y desarrollo organizacional. Dissertare, Revista de Investigación en Ciencias Sociales, 2(1), 129-138.

13. López, P., \& Gómez, R. (2016). Coaching académico para adquirir competencias profesionales. Estudio de caso en la Universidad de Málaga. Opción, 32(10), 95-110.

14. Madera, P. (2016). La gestión del conocimiento como estrategia indispensable en las organizaciones. Revista Agunkuya, 5(2), 29-38.

15. Montero Tapia, I. F., Erazo Álvarez, J. C., Narváez Zurita, C. I., \& Ormaza Andrade, J. E. (2019). Desarrollo organizacional como estrategia de modernización de la calidad del servicio de alimentos y bebidas. Visionario Digital, 112.

16. Musicco, G. (2015). Coaching: conciliación de vida laboral-personal (WLB). Revista del Centro de Investigación. Universidad La Salle., 11(44), 121-142.

17. Narváez Zurita, I., Monagas Docasal, M., \& Erazo Álvarez, J. C. (2019). Las competencias laborales en el sector de textiles y confecciones en la provincia Tungurahua, Ecuador. Cofin Habana, 18.

18. Orellana, I., Paredes, C., Cevallos, E., \& Reyes, M. (2019). Coaching: aplicación a un modelo de Cooperativas en Ecuador. Universidad, ciencia y tecnología, 23(93), 43-54.

19. Piñeiro, M., Martinez, M., \& Guillén, E. (2013). Planificación y organización de la docencia enseñar y aprender mediante coaching educativo. Univest, 1-7.

20. Ramos, E., Sierra, B., \& Roces, C. (2019). Ámbitos de aplicación del Coaching educativo: una revisión bibliográfica del periodo 2013-17. Educatio Siglo XXI, 37(2), 223-244.

21. Robbis, S. (1999). Comportamiento Organizacional. En S. Robbis, Comportamiento Organizacional (pág. 301). California, México: Prentice-Hall.

22. Salazar, M., Hernández, M., Vargas, G., \& Hernández, J. (2017). Impacto del coaching socioformativo como estrategia de formación integral en la industria del alojamiento en México. Revista Interamericana de Ambiente y Turismo., 13(2), 144-156. 
23. Sánchez, J., Gómez, M., \& Molina, W. (2018). Evaluación del desempeño laboral y su incidencia en la productividad en las tortillerías de la localidad de Escárcega. Daena: International Journal of Good Conscience, 13(1), 317-327.

24. Sánchez, J., Lorenzo, A., Jiménez, S., \& Lorenzo, J. (2017). El entrenador como mentor de jugadores en formación: un estudio de relaciones entrenador-deportista positivas. Revista de Psicología del Deporte, 26(1), 95-99.

25. SEPS. (15 de enero de 2018). Informes. Obtenido de Informes: https://www.seps.gob.ec/noticia?seps-presenta-informe-de-rendicion-de-cuentas-2018

26. Whitmore, J. (2003). Coaching: el método para mejorar el rendimiento de las personas. Barcelona: Paidos empresa.

27. Yohalmo, R. (2014). Capacitar o morir: la capacitación de personal como estrategia competitiva (1a ed.). San Salvador: León Editores.

\section{REFERENCES CONSULTED}

1. Aldana, J., \& Piña, J. (2017). Quality of service provided to the client by gym instructors. Interdisciplinary Arbitrated Review Koinonía, 2 (3), 172-197. Recovered from cle/view/59/46

http://fundacionkoinonia.com.ve/ojs/index.php/revistakoinonia/arti-

2. Alvarez, L., Izquierdo, L., Gudiño, L., \& Macias, M. (2018). Educational coaching: development of skills in the higher level student. INNOVA Re-search Journal, 3 (11), 169-182.

3. Alvarez, L., Izquierdo, L., Gudiño, L., \& Macias, M. (2018). Educational coaching: development of skills in the higher level student. INNOVA Research Journal, 3 (11), 169-182.

4. ASESCO. (6 of 2018). Spanish Coaching Association. Obtained from http://www.asescoaching.org/el-coaching/

5. Central Bank of Ecuador. (January 1, 2015). Banco Central del Ecua-dor- Statistics. Obtained from the Central Bank of Ecuador- Statistics: https://contenido.bce.fin.ec/documentos/Estadisticas/SectorReal/CuentasProvinciales/Indicep.htm 
6. CB Biblián. (2019). Report 2019. CB Biblián, 2.

7. Cuadri, J., Fierro, S., \& Palma, I. (2015). The coaching Journal of Education, Motricity and Research, 1 (4), 18-33.

8. Del Río, J., López, N., \& Rodríguez, C. (2015). Coaching: Different concepts from the typologies. Agunkuya, 5 (2), 21-28.

9. Dick, B. (2000). Research in action. In B. Dick, Research in action.

10.EEC. (08 of 2019). Coaching School Obtained from https://www.escuelacoaching.com/

11. ICF. (04 of 2017). ICF Obtained from https://coachfederation.org/

12. Leal, M., Mejías, L., \& Guédez, M. (2017). Ontological coaching as a management approach, for organizational transformation and development. Dissertare, Social Science Research Review, 2 (1), 129-138.

13. López, P., \& Gómez, R. (2016). Academic coaching to acquire professional competencies. Case study at the University of Malaga. Option, 32 (10), 95-110.

14. Madera, P. (2016). Knowledge management as an indispensable strategy in organizations. Agunkuya Magazine, 5 (2), 29-38.

15. Montero Tapia, I. F., Erazo Álvarez, J. C., Narváez Zurita, C. I., \& Ormaza Andrade, J. E. (2019). Organizational development as a strategy to modernize the quality of the food and beverage service. Digital Visionary, 112.

16. Musicco, G. (2015). Coaching: reconciliation of work-personal life (WLB). Journal of the Research Center. La Salle University., 11 (44), 121-142.

17. Narváez Zurita, I., Monagas Docasal, M., \& Erazo Álvarez, J. C. (2019). Labor competencies in the textile and clothing sector in Tungurahua province, Ecuador. Cofin Habana, 18.

18. Orellana, I., Paredes, C., Cevallos, E., \& Reyes, M. (2019). Coaching: application to a model of Cooperatives in Ecuador. University, science and technology, 23 (93), 43-54.

19. Piñeiro, M., Martinez, M., \& Guillén, E. (2013). Teaching planning and organization teaching and learning through educational coaching. Univest, 1-7. 
20. Ramos, E., Sierra, B., \& Roces, C. (2019). Areas of application of Educational Coaching: a bibliographic review of the 2013-17 period. Educatio 21st century, 37 (2), 223-244.

21. Robbis, S. (1999). Organizational behavior. In S. Robbis, Organizational Behavior (p. 301). California, Mexico: Prentice-Hall.

22. Salazar, M., Hernández, M., Vargas, G., \& Hernández, J. (2017). Impact of socioformative coaching as a comprehensive training strategy in the accommodation industry in Mexico. Inter-American Journal of Environment and Tourism., 13 (2), 144-156.

23. Sánchez, J., Gómez, M., \& Molina, W. (2018). Evaluation of labor performance and its impact on productivity in the tortillerías of the town of Escárcega. Daena: International Journal of Good Conscience, 13 (1), 317-327.

24. Sánchez, J., Lorenzo, A., Jiménez, S., \& Lorenzo, J. (2017). The coach as a mentor of players in training: a study of positive coach-athlete relationships. Journal of Sports Psychology, 26 (1), 95-99.

25.SEPS. (January 15, 2018). Reports. Obtained from Reports: https://www.seps.gob.ec/noticia?seps-presenta-informe-de-rendicion-de-cuentas2018

26. Whitmore, J. (2003). Coaching: the method to improve people's performance. Barcelona: Paidos company.

27. Yohalmo, R. (2014). Train or die: the training of personnel as a competitive strategy (1st ed.). San Salvador: León Editores.

C2019 por el autor. Este artículo es de acceso abierto y distribuido según los términos y condiciones de la licencia Creative Commons Atribución-NoComercial-Compartirlgual 4.0 Internacional (CC BY-NC-SA 4.0) (https://creativecommons.org/licenses/by-nc-sa/4.0/). 